\title{
Narrativas em trânsito midiático: Análise dos roteiros da websérie Stufana
}

Diego Luiz Silva Gomes de Albuquerque.

Mestrando no Programa de Pós-Graduação em Artes Cênicas da Universidade Federal da Bahia (UFBA).

Projeto de Pesquisa.

Orientação: Profa. Dra. Catarina Sant'Anna

Dramaturgia, História, Recepção.

Resumo: Trata-se da análise de uma série de ficção científica, com enfoque no melodrama televisivo, Stufana (2009-2012). Esse experimento foi desenvolvido dentro do Projeto Telateatro que investiga o hibridismo entre as linguagens, tendo a dramaturgia como fio condutor dos processos. A série contém cinco episódios; desdobrados em nove para a internet, e um sexto episódio não gravado convertido em uma leitura dramática e uma radionovela. $\mathrm{O}$ projeto pretende descrever as etapas de divisões de episódios, as estratégias de construção da narrativa e analisar a transposição do último episódio para outras linguagens.

Palavras-chaves: dramaturgia, hibridismo, linguagens

Narratives in transit media: Analysis of the scripts the web series Stufana.

Abstract: This is the analysis of a series of science fiction, focusing on television melodrama, Stufana (2009-2012). This experiment was conducted within the Telateatro Project, which investigates the hybrid between the languages, and the drama as a link processes. The series contains five episodes; broken down into nine for the internet, and a sixth episode not written converted into a dramatic reading and a soap opera. The project aims to describe the steps of divisions of episodes, the construction of the narrative strategies and analyze the transposition of the last episode for other languages. Key-words: drama, hybrid, languages

Narración en el tránsito de los medios de comunicación: Análisis de los guiones de la serie web Stufana.

Resumen: Este es el análisis de una serie de ciencia ficción, que se centra en el melodrama para televisión Stufana (2009-2012). Este experimento se llevó a cabo dentro del Proyecto Telateatro, que investiga el híbrido entre los lenguajes y el drama como hilo conductor del proceso. La serie consta de cinco episodios, divididos en otros nueve para Internet y un sexto episodio no grabado y convertido en una lectura dramática y una telenovela. El proyecto tiene como objetivo describir los pasos de las divisiones de los episodios, la construcción de las estrategias narrativas y el análisis de la incorporación del último episodio en otros lenguajes.

Palabras claves: dramaturgia, hibridismo, lenguajes 


\section{Apresentação}

Com a iniciativa de fazer uma introdução prática e investigativa à interpenetração de linguagens que lidam com a narrativa, em 2009, foram criado dois Grupos de Estudos em Artes Cênicas, um sobre dramaturgia e o outro o trabalho do ator, coordenado pelo dramaturgo e videasta Luiz Felipe Botelho, dentro do Projeto TelaTeatro $^{\mathrm{i}}$ da Diretoria de Cultura/ Massangana Multimídia Produções (MMP) pela Fundação Joaquim Nabuco, Recife- Pernambuco.

Os grupos nasceram com a proposta de ampliar os estudos de dramaturgia iniciados com o curso Dramaturgia na fronteira das linguagens em 2008. A partir de exercícios de práticas de escrita dramatúrgica, o curso buscava unir a escrita teatral a uma investigação acerca de conexões com diferentes tipos de narrativas, como a de quadrinhos, cinema, TV, entre outras.

Num trabalho integrado entre os grupos de dramaturgia e de trabalho do ator, desenvolveu-se um estudo sobre o gênero melodramático teatral e construiu-se uma série para ser veiculada na internet - Stufana ${ }^{i i}$ (2009-2012). Esse experimento teve como ponto de partida a criação de um universo ficcional centrado na ideia de uma suposta cidade cristal coberta por um domo de aço e vidro, construída no cerrado brasileiro. Os habitantes daquela cidade ficariam isolados por cinquenta anos e tinham o objetivo de descobrir saídas para os problemas que a humanidade enfrentaria no início do terceiro milênio. Assim, a websérie com cinco episódios, desdobrado em nove para a internet, narra as primeiras histórias dos nove stufanens ${ }^{i i i}$ no mundo exterior.

$\mathrm{Na}$ tentativa de desenvolver esse universo narrativo, o coordenador lançou um desafio para o núcleo de dramaturgia de criar todos juntos um roteiro final para a série, no intuito de concluir aquele exercício. Ao constatar a impossibilidade de gravação, visto que não haveria recursos financeiros, o núcleo decidiu contar a narrativa de Stufana através de outros suportes, como uma leitura dramatizada e a gravação de uma radionovela.

Como integrante do núcleo de dramaturgia, participei intensamente dos processos de criação e produção, adquirindo diversas funções, tais como: roteirista, assistente de produção e direção, produtor, ator, figuração, still e ainda fiquei responsável por escrever o diário de campo sobre cada gravação da websérie. Também, acompanhei todos os ensaios da leitura dramática e da radionovela. A partir disso, com 
a pesquisa, pretenderei descrever as etapas de construção da narrativa, bem como estratégias e a análise da transposição do último episódio para os outros formatos.

\section{O Projeto PROBESH: Eixo teórico-metodológico}

Trata-se de um estudo teórico que propõe uma descrição das etapas do processo de construção da websérie e a análise do último episódio e de sua transposição para outras mídias. Ainda em fase inicial, o projeto está construindo o seu objeto de estudo através de um levantamento bibliográfico que discuta o tema investigado, e uma pesquisa documental dos materiais registrados pelos grupos durante o processo de construção. Será feita também entrevistas, com o coordenador e demais integrantes a fim de coletar o maior número de informações sobre a série. A dissertação será dividida em três capítulos: 1) O percurso da história da construção da série aliados a conceitos teóricos; 2) As estratégias e etapas de construção da escrita da narrativa; 3) Análise do último episódio e suas transposições para a leitura dramática e radionovela.

\section{Do Melodrama à Ficção Científica}

Voltados para uma pesquisa a partir de estudos sobre os gêneros (épico, lírico, dramático e melodramático), os grupos de estudo se dedicaram somente ao último para a construção da websérie, baseados na pesquisa da professora e pesquisadora Ivete Huppes em seu livro O Melodrama - o gênero e sua permanência (2000).

O melodrama, atualmente é um gênero altamente popular entre as mídias existentes (filmes, telenovelas, seriados, entre outros) e estas se apropriam dessa estrutura para construir suas narrativas, pois de acordo com Huppes

\footnotetext{
Por excelência moderno, o melodrama busca deliberadamente a sintonia com o grande público... Quem lhe assegura a continuidade é a recepção positiva. Representações ligadas a estéticas muito diferentes continuam a recorrer ao modelo melodramático, ainda quando seguem propostas estéticas diferentes. (p. 23).
}

Com isso, para entender quais foram os caminhos traçados pelos grupos, na estrutura melodramática, além do livro-base escolhido por eles, se faz necessário na pesquisa um diálogo com Jean-Marie Thomasseau em seu livro O melodrama (2005), pois este faz uma análise histórica e estética desse gênero teatral. 
Além disso, para desenvolver sua narrativa, os grupos escolheram o formato de ficção científica, mecanismo altamente popular nos meios de comunicação como o rádio, o cinema, as séries de televisão e as histórias de quadrinhos.

David Allen ao tentar trazer uma definição de ficção científica nos explica que:

Tudo o que pode ser dito em ficção em prosa, em geral, aplica-se a ficção científica... E como qualquer prosa, os temas de ficção científica preocupamse com a interpretação da experiência e da natureza do homem em relação ao mundo ao seu redor. .A ficção científica se preocupa com as consequências de mudanças em seres humanos, esta mudança pode ser ocasionada pela pura extrapolação de conhecimento científico corrente, para seu desenvolvimento lógico no futuro próximo. (pp. 208, 219)

É com essa prática de criação dramática teatral que nasceu o projeto PROBESH Protótipo Prospectivo Biodomo Estufa Humana - Stufana ${ }^{i v}$, um projeto desenvolvido com base na hipótese que, se a Terra é um microcosmo bem delimitado, será possível analisar problemas e soluções para o planeta através da observação de um contexto similar, de menor proporção, igualmente fechado e delimitado.

\section{Stufana: Etapas de criação}

A websérie nasce entre uma dinâmica entre atores, dramaturgos e público podendo ser divididas em três etapas: A entrevista, a criação dos personagens e a construção dos roteiros.

I. A entrevista - A proposta dessa etapa é colher informações sobre o universo fictício de Stufana em um trabalho que integrasse dramaturgo, ator e público. O coordenador lança um desafio para os dramaturgos, à criação de três personagens habitantes da cidade e, estes dariam uma entrevista aberta ao público, narrando a experiência de viverem isolado por cinquenta anos. Rose, Amadheu e Nina eram os representantes na abertura das portas de Stufana no dia oito de setembro de 2009. Já os atores foram desafiados, em um trabalho de improvisação, a representar esses personagens e responder ás perguntas feitas pelo público e dramaturgos presentes. Ao final do exercício foi feita uma roda para ouvir a opinião do público quanto à ideia proposta e a sensação dos atores em improvisar.

II. A criação dos personagens - Após as impressões da entrevista, os atores partiram para a criação de seus personagens. O eixo teórico foi a partir do conceito de gesto psicológico de Michael Chekhov, em que o exercício dos atores era 
resumir em um único gesto o momento atual de seus personagens e criar uma epígrafe que descrevessem um pouco do momento em que se encontravam. Assim nasceram os nove personagens da série.

III. Construção dos roteiros - A partir dessas descrições dos atores, os dramaturgos foram divididos em núcleos para compor a narrativa de Stufana. O objetivo era gerar uma trama central, ligada à história dessa cidade fictícia que se desenvolvessem em múltiplas subtramas entre os personagens e, assim foram construídos os cinco episódios da série. O último episódio da série foi feito por uma proposta de encerramento do experimento, no desafio de ser escrito por todos os dramaturgos e por falta de financiamento foi convertido em radionovela e leitura dramatizada.

\section{Análise dos Roteiros}

Esta última etapa se concentra o cerne da pesquisa, ou seja, a análise do último episódio e suas transposições para os outros suportes. Antes da análise, já estão sendo analisados os cinco episódios, visto que, compreendemos que estes compõem toda a narrativa.

Para a análise da narrativa me basearei nas pesquisas da autora francesa Anne Ubersfeld, pois sendo a proposta do grupo trabalhar as linguagens através da escritura teatral, o modelo actancial ajuda a encontrar dentro dos roteiros as "matrizes textuais da representatividade" e os "núcleos de teatralidade no texto". Através dessas ideias podemos tecer um diálogo com o teórico francês Etienne Souriau e seu livro As duzentas mil situações dramáticas, para observar na narrativa "as funções dramatúrgicas" construídas pelos grupos.

Por se tratar de um roteiro escrito para televisão, autores como Doc Comparato, Syd Field e os estudos de dramaturgia da roteirista Renata Palottini são de suma importância, pois tratam da criação de narrativas para televisão e cinema e trazem muitas informações úteis sobre essas indústrias de comunicação. Outro autor importante é o professor Luiz Fernando Ramos, visto que ele traz uma ampla reflexão histórica sobre a rubrica e seu papel na literatura dramática.

Para a análise das adaptações, é importante discutirmos o conceito de "Narrativa transmidiática", termo apresentado pelo professor de jornalismo e cinema Henry Jenkins para identificar essa narrativa que transita pelas mídias. Além disso, 
artigos sobre radionovela, televisão, narrativas audiovisuais estão sendo coletados para maior entendimento do assunto.

\section{Considerações}

É importante esclarecer a minha participação com o objeto de estudo e as consequências que emanam desta condição para a realização da pesquisa. Pretendo segmentar os momentos em que cada um desses papéis se estabelece, a fim de obter um registro analítico ao mesmo tempo, e paradoxalmente, distanciado e participativo das atividades realizadas dentro do grupo. Em consequência, a pesquisa será pautada na geração de fontes primárias através dos registros das etapas de criação do grupo.

\section{Referências}

ALLEN, David. No mundo da ficção científica. São Paulo: Summus Editorial, 1974. COMPARATO, Doc. Roteiro - arte e técnica de escrever para cinema e televisão. Rio de Janeiro: Nórdica, 1983, $5^{\text {a }}$ edição.

CALABRE, Lia. No tempo das radionovelas. UMESP, Intercom - Sociedade Brasileira de Estudos Interdisciplinares da Comunicação. XXX Congresso Brasileiro de Ciências da Comunicação, Santos, 29.08 a 2.09 de 2007. Disponível em: <http://www.intercom.org.br/papers/nacionais/2007/resumos/R0183-1.pdf>.

FIELD, Syd. Manual de Roteiro. Rio de Janeiro: Objetiva, 1995.

FERREIRA, Carol do Espírito Santo. A televisão como texto: notas sobre a recepção prefigurada nos textos televisivos de ficção. UMESP, Intercom - Sociedade Brasileira de Estudos Interdisciplinares da Comunicação. XXX Congresso Brasileiro de Ciências da Comunicação, Santos, 29.08 a 2.09 de 2007. Disponível em: <http://www.intercom.org.br/papers/nacionais/2007/resumos/R0183-1.pdf>.

HUPPES, Ivette. Melodrama: o gênero e sua permanência. São Paulo: Ateliê editorial, 2000 .

JENKINS, Henri. Cultura da convergência. Tradução Suzana Alexandria. $2^{a}$ edição. São Paulo: Aleph, 2009.

PALLOTTINI, Renata. Introdução à Dramaturgia. São Paulo: Ática, 1988. Série Princípios. 1989. Dramaturgia: construção de personagem. São Paulo: Ed. Ática, Dramaturgia de televisão. São Paulo: Ed. Moderna, 1998. 
RAMOS, Luiz Fernando. O parto de Godot e outras encenações imaginárias: a rubrica como poética da cena. São Paulo: HUCITEC/ FAPESP, 1999.

RENÓ, Denis Porto. Narrativa audiovisual: uma possibilidade de interatividade na Internet. UMESP, Intercom - Sociedade Brasileira de Estudos Interdisciplinares da Comunicação. XXX Congresso Brasileiro de Ciências da Comunicação, Santos, 29.08 a 2.09 de 2007.2 Disponível em: <http://www.intercom.org.br/papers/nacionais/2007/resumos/R0183-1.pdf〉.

SOURIAU, Etienne. As duzentas mil situações dramáticas. São Paulo: Ática, 1993.

THOMASSEAU, Jean-Marie. O melodrama. Trad. Claudia Braga e Jacqueline Penjon. São Paulo: Perspectiva, 2005.

UBERSFELD, Anne. Para Ler o Teatro. São Paulo: Perspectiva, 2005.

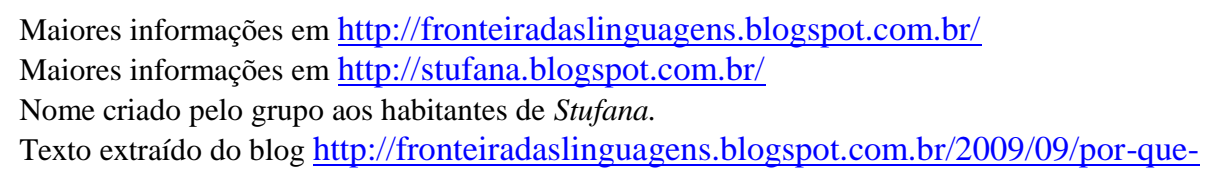

